\title{
10. ECONOMIC TRANSFORMATION ON \\ BENEFIT SHARING OF HYDROPOWER PROJECT AREA
}

- Usha Khatiwada ${ }^{10}$

\begin{abstract}
Major problem of Nepalese economic transformation is lack of educational willingness of development practiceners. This study has been conducted to analyze the theories of economic transformation, to check the initiation of economic transformation in Nepal, to analyze the rural electrification and benefit sharing. It is based on secondary information of library method. It is a review of related documents of economic transformation, benefit sharing and hydropower projects of Nepal. The study shows that theories on Economic Transformation are necessary to revise; Economic Transformation in Nepal is yet to start; Rural Electrification is not economic transformation from hydropower projects in Nepal; Benefit sharing in Nepal is not satisfactory.
\end{abstract}

Keywords: Benefit Sharing, economic transformation, hydropower

\section{Background}

The major bottleneck in Nepalese economic transformation is employment pattern (Bhatta, 2014). It is believed that increased employment opportunities are the prerequisites for continued and sustained economic growth. In Nepal, we can observe a massive underemployment with ery low productivity in agriculture. The opposite is the case of services as the contribution to economy is more than half but it provides employment for only 15 percent of work force (Bhatta, 2014). Thus the hydropower projects can provide the employment opportunities, business opportunities, and many more economic multiplying activities.

Economic transformation is the positive change on human economic life from different development projects. In development economics, economic transformation refers to the continuous process of moving labor and other resources from lower to higher-productivity sectors raising withinsector productivity growth. Economic transformation, as part of development, can be defined as a dynamic process through which a country's economy, society and institutions modernize and move to more developed levels (Clemens \& Xinshen, 2008). As such, economic transformation emphasizes the movement from low to high productivity activities within and across all sectors. Thus hydropower projects could be the panacea of poverty alleviation.

\section{Reviews}

The study is completely based on library method. A massive literature review has been conducted to draw the conclusion. This movement of resources from lower productivity to higher productivity activities is a key driver of economic development (Clemens \& Xinshen, 2008). Within sector productivity growth entails the adoption of new technologies and management practices that

10 Ms. Khatiwada is a PhD Scholar at TU and involved in Micro Hydro and Insurance. 
increase the efficiency of production. It can come about as a result of theincreased efficiency of existing firms or as a result of the reallocation of resources away from the least productive firms towards more productive firms. As such, a specific type of structural economic transformation is occurring - one where labor moves to a more productive sector/activity, but not within the national economy (Basnett, et al., 2014) . When a hydropower project will start in a certain place, it creates job and increases the employment opportunities.

It will bring a tremendous change-economic transformation, as structural economic transformation involves the movement of labor from low to higher productive activities. This could entail movements within the sector (for example from subsistence farming to high value crops) or between sectors (for example from agriculture to manufacturing to services). The importance is in the returned labor accrues, higher wadges and the associated developmental benefits to the household, for example in health and education. As such, structural economic transformation must be viewed in terms of productivity changes (within or between sectors) (Basnett, et al., 2014). It can be easily observed if we visit the buffer zone of mega projects.

Economic transformation can be measured through production/value-added measures and tradebased measures. Production-based measures include: sector value added and employment data, to show productivity gaps between sectors; and firm-level productivity measures, to examine average productivity levels of firms within one sector (Clemens \& Xinshen, 2008). Tradebased measures include: measures of revealed comparative advantage to show the levels of specialization of a country in certain exports; and export diversification measures such as those produced by the International Monetary Fund. Economic transformation is commonly defined as a process in which an increasing proportion of economic output and employment are generated by sectors other than agriculture. Low levels of productivity have inhibited meaningful structural economic transformation - where labor moves from low productivity activities to those with higher productivity and returns. With the manufacturing sector in stagnation, and with limited absorption capacity within the services sector, many Nepalese exit the national labor market to find employment abroad (Basnett, et al., 2014).

\section{Discussion and Analysis}

\section{Theories on Economic Transformation are necessary to revise}

This process of transformation means the shift from agricultural-based societies to urban, industrial and/or service-based economies with sustained high GDP growth rates (Mugerwa, 2016).For the last 15 years the world has been guided by Millennium Development Goals (MDGs) which have since 2016 been succeeded by SDGs and will guide the world for the next 15 years till 2030. The SDGs, officially known as Transforming our world: the 2030 Agenda for Sustainable Development, are an intergovernmental set of aspiration goals. The 2030 Agenda is a global commitment to achieving sustainable development in its three dimensions of economic, social and environmental, in a balanced and integrated manner (Mugerwa, 2016). The Agenda is a plan of action that is centered on people, the planet and prosperity. Its aim by 2030 is: to 
end poverty and hunger everywhere; to combat inequalities within and between countries; to build peaceful, just and inclusive societies; to protect human rights and promote gender equality; to ensure the lasting protection of the planet and its natural resources; and to create conditions for sustainable, inclusive and sustained economic growth, shared prosperity and decent work for all, taking into account different levels of national development and capacities (Mugerwa, 2016).These sustainable goals are easily achievable for Nepal, due to the interest of high foreign assistance Nepal government is lowering its economic status. So it seems to be revised

Schultz was among the first economists to emphasize that productivity-led agricultural transformation can make a much more important contribution to economy-wide transformation than merely providing surplus labor and savings to support industrialization (Clemens \& Xinshen, 2008). According to Schultz efficient but poor hypothesis, farmers should be seen as entrepreneurs even within traditional agricultural systems. The low marginal productivity seen in agriculture before transformation is due to the fact that factors employed in agriculture are traditional. Incentives for farmers to invest in these traditional factors are low unless farmers have the opportunity and incentive to transform the traditional agriculture of their forefathers or ancestors (Clemens \& Xinshen, 2008). In Schultz' view, the existence of a micro foundation for farmers to adopt modern technologies can make agriculture an important driver of growth. He emphasizes the role of agricultural productivity growth, stating that "unless technological progress in agriculture is sufficiently rapid to outpace the growth of population and the force of diminishing returns in land and other factors, the industrial sector may not become economically viable". Schultz's Theory is very important to analyze the economic transformation but it is also not free from criticisms.

Lewis' dual economy theory was the first seminal contribution to understanding how technology led productivity growth in the industrial sector leads to economic transformation. Observations on the streets of Bangkok inspired Lewis to hypothesize the existence of a large traditional sector in which "the marginal productivity of labor is negligible, zero or even negative" in many lowincome developing countries (Clemens \& Xinshen, 2008). The difference between a leading modern sector (often the industrial sector) with higher productivity and a lagging traditional sector (often the agricultural sector) with lower productivity, combined with an unlimited supply of labor from this traditional sector (which keeps economy-wide wages down), allows production to grow in the economy through the migration of labor from the traditional sector to the modern sector (Clemens \& Xinshen, 2008). Same as Schultz Lewis is also on the same way on its ideologies however it is time to redefine it locally.

Economic transformation from rural agricultural to modern industrial or service sectors is the fundamental requirement to achieve high and sustainable growth (Bhatta, 2014). This can be said as the rapid and sustainable economic development in most of the developed as well as emerging economies has been achieved with the permanent shifts in their economic structure over the long-run. They have experienced a gradual transformation of the economy from rural subsistent agriculture to the modern industrial and then ultimately to the service dominant (Bhatta, 2014). 
Economic transformation is about changing the nature of jobs, of changing what people do, where they do it and how they do it. The jobs diagnostics undertaken by the World Bank clearly show that the degree of economic transformation determines how widespread job creation will be and the extent of productivity and income gains.

\section{Economic Transformation in Nepal is not yet started}

Nepal's economy depends on its natural resources. Water and forests, if well managed and maintained, can become resource bases for economic transformation process. Moreover, Nepal has the potential to decouple growth from rising carbon emissions by leveraging hydropower as a source of energy for the economy. By increasing the amount of low-carbon electricity generated through hydropower, Nepal can remove a major constraint to growth across the economy - the lack of reliable and regular energy supply (Basnett, et al., 2014). In addition, providing electricity in rural areas will contribute to expanding the area of land under irrigation, and further diversify the rural economy, allowing poor households to become more integrated in the economy. In the long term, surplus energy from hydropower can be sold to India to generate foreign currency reserves, thus contributing to reversing Nepal's trade deficit (Basnett, et al., 2014). It has not shown any substantial changes on livelihood of people of hydropower project areas. Economic transformation continues to escape Nepal. Weak productive capacity has resulted in low levels of economic development and per capita income, and a large majority of labor is still involved in low productive agricultural activities (Basnett, et al., 2014). With the manufacturing sector stagnant, and low labor absorption capacity in the service sector, economic alternatives for improving household well-being have not been forthcoming from the national economy. Consequently, a large number of workers choose to migrate to foreign labor markets in search of better jobs (Basnett, et al., 2014). Entire development projects should be revised for rapid economic development.

\section{Rural electrification is not economic transformation from hydropower projects in Nepal}

Developing mini hydropower infrastructure provides rural households and businesses electricity, which contributes to higher farming and processing output in rural areas. This also reduces dependence on wood for fuel. Rural electrification can lead to a virtuous circle where increased output drives more investment, in turn spurring more production (Basnett, et al., 2014).Developing large dams and hydropower infrastructure can also generate electricity for rural areas, but also serve manufacturing industries and service sectors, addressing a major constraint to growth for these sectors (Basnett, et al., 2014). Water resources It is estimated that the Nepal contains $2.27 \%$ of world's fresh water resources. There are over 6,000 rivers and rivulets and 660 lakes with annual runoff of 225 billion cubic meter (BCM) of which only 15 BCM has been utilized. Groundwater potential is $12 \mathrm{BCM}$, of which annual withdrawal is $0.756 \mathrm{BCM}$ for irrigation and $0.297 \mathrm{BCM}$ for domestic uses. A total of 1.2 million ha land is irrigated ( $68 \%$ of the total irrigable land, DOI 2007), of which 0.93 million ha is irrigated by surface and 0.28 million ha by groundwater. Irrigation capability. Total hydropower generated in the county is $634 \mathrm{MW}$ despite the economic potential to generate over $42,000 \mathrm{Mw}$ (Bhatta, 2014). It has brought the social change in livelihood 
however until it economically shows the tangible result in GDP and employment opportunities at local level it should not be addressed as economic transformation of people.

A positive outcome of rural electrification would be the potential to reduce the costs of irrigation use and expansion in new areas. At present, many farmers rely on expensive diesel pumps or forego irrigating during power (Basnett, et al., 2014)losses which would occur less frequently with a regular power supply. Meeting domestic energy needs means Nepal would no longer need to buy electricity from India, but could instead sell it, improving the balance of trade and, with it, wider macroeconomic conditions that determine how attractive Nepal is as an investment destination. The sum of these changes is more low-carbon growth and poverty reduction(Basnett, et al., 2014). Although it is a very strong step toward economic transformation.

\section{Benefit sharing in Nepal is not satisfactory}

The contemporary discourse on 'benefit sharing' parallels a broader reframing of hydropower development as an important vector for sustainable development and an increasing focus on resolving embedded issues of social and environmental equity (Shrestha, et al., 2016). The 2000 World Commission on Dams, the 2010 Hydropower Sustainability Assessment Protocol and the emergence of the concept of integrated water resources management (IWRM), for example, are all evidence of this increasing interest in sustainability standards and the idea that the requirements and goals of sustainability have evolved over the years (Shrestha, et al., 2016). Increasing requirements for 'social and environmental mitigation' and new expectations for 'corporate social responsibility (CSR)' indicate a similar shift in the social dimensions of development projects.

'Benefit sharing' as a formal concept is relatively new in Nepal, the analysis of the hydropower sector in Nepal indicates that a variety of models and practices of benefit sharing have co-evolved with efforts to promote hydropower development over time. These patterns reflect broader patterns of success and failure in Nepal's hydropower sector, but also a series of unique innovations and solutions emerging from the process of negotiation with the different stakeholders seeking benefits. In parallel, a variety of overlapping definitions of what benefit sharing is and what it should be have also arisen, creating a robust and dynamic discourse that places Nepal at the leading edge of the global conversation on benefit sharing in the hydropower sector (Shrestha, et al., 2016). It should be redefined and imposed in Nepalese modality. Although legal and regulatory frameworks are key factors affecting the benefit sharing arrangements, the design and realization of any benefit-sharing program in Nepal rests on a process of negotiation.

Despite this complexity, the comprehensive review of practices and policies of benefit sharing by 18 different hydropower projects across Nepal suggests that the field of benefit-sharing practices is trending toward coherence. Thus, although it would be inappropriate to try to create a 'onesize fits all' policy, the time has come to establish a more comprehensive policy framework that can guide project developers seeking to establish benefit sharing programs and frame the process of negotiation in a way that might yield more effective solutions to conflicts over hydropower development (Basnett, et al., 2014).It is important to establish a clear definition of 'benefit sharing' 
as a concept and a shared system of classification for the diverse benefits arising from hydropower development (Shrestha, et al., 2016)

Environmental issues must be considered within larger decision making about water resources management and within the global paradigm of the water, food, and energy nexus. In the current political and economic climate, many people consider environmental safeguards to be an additional barrier to hydropower development and an additional cost preventing the realization of Nepal's hydropower possibilities - a perspective that reflects an imbalance between short-term and long-term needs (Bhatta, 2014).

\section{Conclusion}

Thus, finding the appropriate mechanism for economic transformation, sharing benefits on or from hydropower projects require balancing the competing interests and agendas of differentlypositioned project stakeholders - from the project developer, to government actors and policy makers, to institutional investors and donor agencies, to consumers and electricity users and project-affected populations. In conclusion, Theories on Economic Transformation are necessary to revise; Economic Transformation in Nepal is not yet started; Rural Electrification is not economic transformation from hydropower projects in Nepal; Benefit sharing in Nepal is not satisfactory.

\section{References}

Basnett, Y., Hanley, G., Howell, J., Harry, J., Lemma, A., \& Pandey, P. (2014). Structural economic transformation in Nepal: A diagnostic study submitted to DFID Nepal. Kathmanu: DFID Nepal.

Bhatta, G. R. (2014). Structural Change and Per Capita Income in Nepal: Empirical Evidences. NRB Economic Review NRB-WP-23, , 41-60.

Clemens, B., \& Xinshen, D. (2008). Economic transformation in theory and practice: What are the messages for Africa? . Washington, DC: Regional Strategic Analysis and Knowledge Support System, International Food Policy Research Institute .

Mugerwa, K. (2016). Socio-economic transformation in Uganda : for attainment of Middle Income Status . Luwero: National Planning Authority Uganda.

Shrestha, P., Lord, A., Mukharji, A., Shrestha, R. K., Yadav, L., \& Rai, N. ( 2016). Benefit Sharing and Sustainable hydropower: Lessons from Nepal. Kathmandu: International Centre for Integrated Mountain Development and Niti Foundation. 